\title{
Developing Vocabulary by Integrating Language and Content
}

Stephen Dunbar

The following article outlines an approach to the teaching of vocabulary that encourages students to apply the cognitive skills that they use in their academic tasks to the learning of new vocabulary items. The approach is described as it was used with a class of sccondary students who, although many are Canadian born, lack proficiency in the use of academic language. This approach reinforces higher cognitive thinking skills by having students classify new vocabulary items they have to learn, and then having them explain the principles behind the classification system they have chosen. By doing this, students are better able to visualize the relationships that exist amongst the words they are learning. As a result, the learning of vocabulary is integrated into a larger, more meaningful unit of language.

The following is a description of an approach to the teaching of vocabulary that integrates the teaching of language and content. It is designed to encourage students to employ the same cognitive skills to build their vocabulary knowledge that they use for all of their academic tasks. This approach reinforces the use of higher cognitive thinking skills by having students classify vocabulary that they need to learn and then having them explain the principles behind the classification system they have chosen. In this way, vocabulary becomes part of a larger, more meaningful unit of language and knowledge.

The approach will be described as it has been implemented with a Grade Eight English class composed of students that have had limited success in subjects that require the use of academic language-typically language that abstracts, deals with concepts, and is often distant from the present. The class is typical of many classes in large urban areas in that it reflects the cultural and linguistic diversity common to these centres. For example, over $80 \%$ of the students in the class are Canadian born, but over $75 \%$ speak a language other than English as a first language. This, in part, compounds the challenge these students face when confronted with academic tasks. One challenge these students face is learning to cope with the large number of new words that they encounter in their content courses. 


\section{PROCEDURE}

To assist the students in their development of new vocabulary, the following procedure has been used:

\section{Day 1}

Students present individual lists of words (ten each). These words are self selected from their subject classes (Social Studies, Science, Math, P.E., etc.) or from words they encounter outside the school setting. The students make two copies of their words-one for them to keep and one for the teacher to check over.

Students then work in pairs to examine ways that their words could be grouped, or classified. They are encouraged to classify in a variety of ways. They might classify by subject, part of speech, spelling patterns, or use some other criteria that shows relationships among the words.

This activity requires the students to think about the meanings of the words in relation to each other and provides opportunity to develop oral skills to discuss these relationships.

\section{Day 2}

The lists that were turned in are returned with comments: spelling errors corrected; questions asked about the need for certain words; questions about meanings of words, etc. Students then make any necessary changes to their lists and return the teacher's copy. On this day they are also given class time to practise the spelling of the words with a partner.

Following the practice, students are asked to show how they have classified their words by placing their classification trees on the board. Other students are then asked to explain what organizational pattern they think a particular student has used. The student then has an opportunity to explain how and why the words are classified in a particular fashion.

\section{Day 3}

On the third, or final, day of the class, the students are asked to spell the words. To do this, the students are paired off and given a copy of each other's vocabulary list. They then quiz each other using the list that they have been given.

Each student then draws a classification tree of his/her words and writes a short explanation of how the words have been classified. 


\section{CLASSIFYING THE WORDS}

What makes this approach challenging is the use of classification and the explanation of the principles that have been used to develop that classification system. Classifying the words forces the students to think beyond the words in isolation. Each word has to be placed in some meaningful way in relation to all the other words in their list. This requires examining the words and deciding how each of the words is related to their overall studies.

To illustrate this, samples of vocabulary lists, along with classification systems students have used to organize the lists, are given below. The classification trees are, for reasons of space, not given in their complete form.

\section{Student A}

Words: sword, automobile, dagger, airplane, eraser, motorcycle, stencil, protractor, sharpener, compass

Classification:

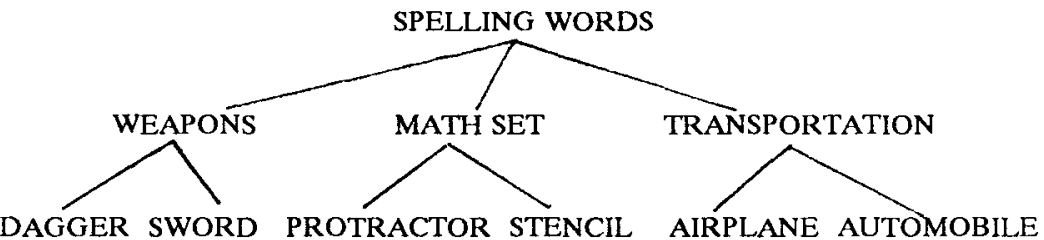

\section{Student B}

Words: light ray, real ray, reflected ray, normal ray, translucent, reflection, transparent, opaque, convex, concave

Classification:

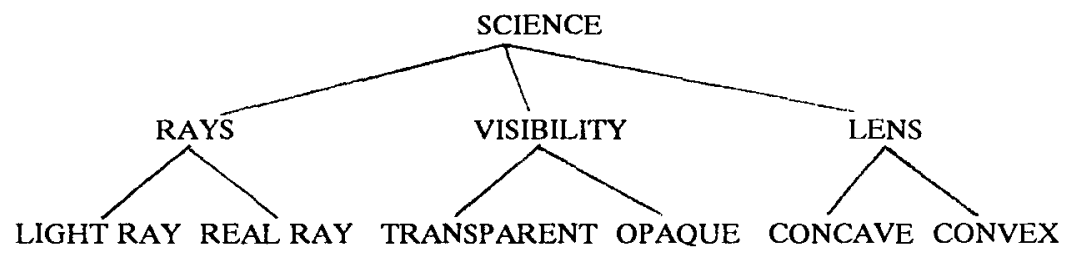

Classifying information is an integral part of our lives academically, socially and personally. Who and what we are is 
determined by the "groups" we place ourselves in. We define who we are by these measures. Scientists similarly define matter by determining what its properties are and by defining its states. Social scientists classify government systems, belief systems and eras. Record shops, supermarkets, and hardware stores organize their merchandise based on some form of classification. The point is that classification is not a new concept to anyone who has experienced any number of years of life experience. Generalizing the concept of classification, however, is not something that many of us have probably considered at a conscious level. Being able to classify allows us to see relationships and differences among the various aspects of our lives and studies. It also allows us to see that there is no one, correct, way to classify. A classification system serves a particular, not a universal, purpose.

Asking students to classify their vocabulary words, therefore, provides an opportunity to bring to a conscious level a form of knowledge that is generally not thought about. It also provides an opportunity to explore a variety of ways that one can use to organize ideas, words, or concepts, and encourages students to view knowledge from a multiplicity of perspectives.

\section{PRINCIPLES OF CLASSIFICATION SYSTEM}

Following this, the students are asked to write a short paragraph to explain their own classification system. This aspect to of the program challenges the students to explain their organizational choice. The following paragraphs are included to illustrate how students have explained their classification systems.

\section{Student A}

All of these words are spelling words. There are three subtitles: weapons, transportation, and math set. Dagger and sword go under weapons because these are two kinds of weapons. Automobile, airplane, and motorcycle go under transportation because they all have to do something with transport. Sharpener, eraser, compass, stencil, and protractor go under math set because they all are part of a math set.

\section{Student B}

I have grouped my spelling words under Science. Under Science I have 3 groups: rays, visibility and lens. Under rays, I have 5 different rays which are light rays, real rays, reflected rays, normal rays, reflections and reflected. I have grouped 
these words there because they show different rays. Under visibility I have the words transparent, translucent and opaque. I have grouped these words together because they all have something to do with sight. For example, transparent means that you can see clearly. Translucent means that you can see through but not clearly, and opaque means you can't see through at all. Under lens, I have the words convex and concave. Convex and concave are two lens shaped like... (student did not complete this portion)

This part of the exercise reinforces the use and spelling of the words they have selected and also gives students a rare opportunity to explain to the teacher something that the teacher does not necessarily know-the principles they have used to classify their words.

All classification systems are based on some principle. There is a "why," a reason, for grouping ideas in certain ways. The exercise that has been described encourages students to examine what their reasons are for grouping their words in a particular fashion. Once this has been established, it is possible to evaluate how useful a particular classification system is.

\section{BACKGROUND}

This approach to building vocabulary is based on Mohan's (1986) "Knowledge Framework." According to Mohan's theory, every task "has a pattern of action which includes description, sequence, and choice, and involves background knowledge which includes classification, principles and evaluation" (p. vi). Approaching vocabulary development from this perspective requires students to use each of these forms of knowledge. In this process the students are involved in:

- Evaluating which words, out of all the possible words they are exposed to, are going to be most useful for them to know.

- Choosing from this large list of possible words, the ten they want/need to learn.

- Becoming more familiar with the patterns/sequence of possible English spellings, and becoming more aware of words that have origins from other languages.

- Learning the specific ten words they have selected.

- Classifying the words so that they are not seen in isolation, but related in various ways to other words, ideas, or concepts. 
- Explaining the principles by which they have chosen to organize their words, thereby taking responsibility for the final product and in turn being able to evaluate what they have done.

\section{INTRODUCING THE PROCEDURE}

Depending on the students one works with, it may be necessary to introduce this approach gradually. For the class that was described earlier, the students initially were asked only to select their vocabulary words. The classifying was added later. Their explanation for the classification system was added last. At each stage, there was discussion about how words were selected, the varieties of ways the words could be classified, and the various ways of expressing their reasons, or principles, for selecting a specific classification system.

As the students worked through these activities they shared their lists of words, and explained why they had chosen them, thereby gaining expertise and skills in performing this aspect of the task. Students also had an opportunity to work with lists from other students, exploring ways that different lists of words could be classified, working out various classification systems, and examining the different principles used by their classmates to organize in various ways. Finally, they had an opportunity to suggest how students could express their reasons for their classification systems. This provided language input which brought the task beyond the word and sentence level. In addition, because the suggestions were coming from their peers, the language input more closely matched what the students were capable of processing, and gave students an opportunity to explore and offer alternative forms of expression.

\section{DISCUSSION}

In this approach, vocabulary development is elevated to a level that shows its relevance to all subjects, both in and out of school. In addition, it has demonstrated to the students described in this paper that they need to use the same thinking skills for learning new vocabulary that they use in other academic tasks.

A further benefit is that this is another way of integrating language and content. The importance of using language to express relationships becomes relevant to all subject areas. Teachers of specific content courses, such as science or social studies, can gain a better understanding of how their students perceive relationships, and reasons they have for organizing their information in various 
forms. For example, when one student classified Michelangelo, Jan van Eyck and Albrecht as artists, it was possible to question the student as to whether there were ways of classifying the names more specifically-perhaps by whether they painted or sculpted; by country of origin; by type of subject they were interested in. By doing this the students are challenged to think more deeply about the possible levels of classification. Another example that provided useful information about how a student was interpreting information was when the student classified Buddhism, Hinduism and Jesus under religions-confusing founders of religions with names of religions. This information is valuable because it gives teachers opportunities to find out where students have understood the material as well as where they have had difficulty conceptualizing information correctly. It also provides a chance for both teachers and students to discuss these issues.

\section{CONCLUSION}

Using an approach such as this can be useful to both teacher and student. Each gains a better understanding of how the other is organizing and conceptualizing the information that is being presented; each gains an appreciation for the variety of ways that specific information can be organized; and at the same time, each is becoming more aware of the general nature of information organization. Vocabulary development, therefore, becomes more than a word level focus on language. It becomes a vehicle that can be used to help students learn about the structure and nature of knowledge.

\section{THE AUTHOR}

Stephen Dunbar is a teacher with the Vancouver School Board, Vancouver, B.C. He has worked with the development of materials at both the school and district level to help teachers coordinate the teaching of language and content. In addition to working with the Vancouver School Board, his experience includes teaching English overseas, working in the area of teacher training, and teaching ESL at various levels, from elementary age students to adults.

\section{REFERENCE}

Mohan, B. A. (1986). Language and content. Reading, MA: Addison Wesley. 